\title{
Treatment of Pellucid Marginal Degeneration
}

\author{
${ }^{1}$ Abdelsattar N Farrag, ${ }^{2}$ Ahmed A Hussein, ${ }^{3}$ Shiji Ummar
}

\begin{abstract}
Purpose: To summarize the recent trends in the treatment of pellucid marginal degeneration (PMD) based on available published data.
\end{abstract}

Method and literature search: A PubMed search was conducted with combinations not limited to the following search terms: Pellucid marginal degeneration, Corneal ectasia, Corneal collagen cross-linking (CXL), Intracorneal ring segments (ICRS), Contact lens, Keratoplasty in corneal ectasia. A review of the search results was performed and relevant articles to the topic were included.

Summary: Ophthalmologists have got a wide array of therapeutic modalities for the management of PMD. However, the key to optimal treatment is careful clinical assessment of patients and their visual requirements and tailoring the treatment to individual patients.

Keywords: Corneal collagen cross-linking, Corneal ectasia, Intracorneal ring segment, Keratoplasty, Pellucid marginal degeneration.

How to cite this article: Farrag AN, Hussein AA, Ummar S. Treatment of Pellucid Marginal Degeneration. Int J Kerat Ect Cor Dis 2017;6(2):87-91.

\section{Source of support: Nil}

Conflict of interest: None

\section{INTRODUCTION}

Pellucid marginal corneal degeneration is a bilateral, noninflammatory, corneal ectasia, most frequently involving the inferior peripheral cornea in a crescentic pattern. The corneal thinning usually arises between the 4 and 8 o'clock position and protrusion occurs as a result of this thinning. ${ }^{1-3}$ Schlaeppi ${ }^{4}$ was the first one who used the term "pellucid," meaning clear, to signify the clarity of the cornea despite the presence of corneal ectasia. It is usually bilateral and asymmetrical; nevertheless, unilateral cases are reported. ${ }^{5,6}$

\footnotetext{
${ }^{1}$ Staff Registrar, ${ }^{2}$ Resident, ${ }^{3}$ Cornea Specialist

${ }^{1}$ Department of Ophthalmology, Singapore National Eye Center Singapore

2Department of Ophthalmology, Baladi Foundation, Aswan, Egypt

${ }^{3}$ Department of Ophthalmology, Al Nahdha Hospital, Muscat Oman

Corresponding Author: Shiji Ummar, Cornea Specialist Department of Ophthalmology, Al Nahdha Hospital, Muscat Oman, Phone: +96893504023, e-mail: dr.shijiparvez@yahoo. co.in
}

Although PMD classically has been affecting the inferior cornea, superior PMD has also been reported, and we should consider it in the differential diagnosis of superior corneal ectasia. ${ }^{7}$ The ectasia in PMD causes progressive diminution of both uncorrected and corrected visual acuity as a result of high against-the-rule astigmatism. ${ }^{1,2}$

The condition is most commonly affecting males and usually presents between the 2 nd and 5th decades of life. ${ }^{3,8}$

The PMD can be diagnosed classically by slit-lamp examination, which shows a clear band of inferior corneal thinning extending from 4 to 8 o'clock. There is typically a 1 to $2 \mathrm{~mm}$ of uninvolved normal cornea. The maximum point of protrusion in PMD occurs in the area superior to the thinning. This is considered one of the important points in differentiation with keratoconus, in which the maximum protrusion is within the area of thinning. ${ }^{9-11}$ Corneal topography with classical pattern of crab-claw appearance is not diagnostic for PMD, as it can present with inferior keratoconus. So, it is recommended to perform more detailed analysis with slit-lamp microscopy, topography, anterior and posterior elevation maps by Scheimpflug imaging and full pachymetric maps that shows $12 \mathrm{~mm}$ of corneal coverage for improving the diagnostic accuracy for PMD. ${ }^{12}$

Management modalities of PMD can be broadly classified as:

- Corneal rehabilitation treatment which includes:

- Nonsurgical: spectacles, contact lenses

- Surgical: ICRS and CXL

- Toric intraocular lens (IOL) implantation

- Corneal replacement surgery which includes:

- Full thickness or penetrating keratoplasty (PKP): oversized central PKP/inferiorly decentered PKP, lamellar keratoplasty (LK), simultaneous central PKP, and inferior peripheral LK, intrastromal LK, crescentic wedge resection, epikeratophakia, and thermokeratoplasty.

The aim of this article is to review the current treatment modalities of PMD.

\section{NONSURGICAL CORNEAL REHABILITATION TREATMENT}

Most patients with early and moderate PMD can be visually rehabilitated by spectacles or contact lenses. 3,8

In the early stages of PMD, soft toric lenses can be an option for improvement in visual acuity. 
In moderate PMD, treatment usually requires the use of large-diameter rigid, gas-permeable lenses due to the development of irregular astigmatism and progression of corneal irregularity. ${ }^{8,13}$ In addition, specialized contact lenses, such as reverse geometry lenses and "bi-toric" lenses can be useful in the management of moderate PMD. ${ }^{14,15}$

In advanced PMD, the scleral contact lens is a helpful nonsurgical treatment when the fitting with corneal lenses is extremely difficult because of the peripheral location of the ectasia. ${ }^{16}$

Scleral lenses are large-diameter gas-permeable lenses that completely vault the cornea and rest on the sclera. Many studies reported the successful use of scleral lenses in the treatment of ocular surface disorders, postkeratoplasty patients, and advanced corneal ectatic disorders. ${ }^{16-18}$

In a recent study evaluating the success of prosthetic replacement of the ocular surface ecosystem (PROSE) in PMD patients, a significant improvement in visual acuity with PROSE (Boston Foundation for Sight, USA) is reported in all patients with PMD after failure of all other nonsurgical options. However, we should be careful while prescribing these lenses at the advanced stage of the disease as the risk of hydrops is high in these patients. ${ }^{19}$

Also, another study reported success in the use of scleral Misa1 lenses (Microlens Contact lens Technology, Arnhem, Netherlands) to improve visual acuity in long-term follow-up in patients with PMD, when any other optical modalities failed, and they recommend it for moderate advanced PMD when other types of contact lens cannot be fitted or in cases of poor operative prognosis and for patients who refuse surgical intervention. ${ }^{20}$

\section{SURGICAL CORNEAL REHABILITATION TREATMENT}

\section{Intracorneal Ring Segment}

Intracorneal ring segments are small pieces made of polymethylmethacrylate, which are implanted in the deep corneal stroma, aiming for modifications of corneal curvature and refractive changes. This notion was proposed by Reynolds in 1978. The first implants were full rings implanted into a circumferential corneal channel through a peripheral single corneal incision. Then to decrease the rate of incision-related complications and make it surgically easier, the rings were changed to the C-shape range, and they were renamed as ICRS. ${ }^{21-23}$

The ICRS is used in early-to-moderate PMD for deferring corneal transplant and improving tolerance of contact lens. The principle of using this originated from what was demonstrated by the addition of extramaterial at the normal corneal midperiphery, which results in a forward displacement of the anterior surface at this area. This causes a peripheral steepening and a flattening of the central part of the anterior cornea due to the morphologic structure of the corneal lamellae. ${ }^{24}$ The same principle can be applied in cases of PMD resulting in decreasing and centralization of the peripheral corneal protrusion, inducing a significant change in corneal asymmetry and refraction.

The implantation of ICRS in PMD proved to be effective in the improvement of visual outcome either by manual or femtosecond surgery. ${ }^{25-31}$

A case report showed improvement of visual acuity after femtosecond implantation of a single ICRS in superior PMD. However, follow-up was only for 3 months. ${ }^{32}$

The ICRS implantation may be associated with postoperative complications, which include segment extrusion, corneal neovascularization, infectious keratitis, channel deposits around the ring, ring segment migration, epithelial plug at the incision site, corneal melting, and night halos. ${ }^{33}$

Limited number of case reports or case series of ICRS implantation in PMD may be due to rare presentation in clinical practice and that ICRS implantation is limited to specific criteria, which may not be fit for most patients. Future studies are recommended with larger number of patients.

\section{Collagen Cross-linking}

Wollensak et $\mathrm{al}^{34}$ demonstrated the effects of CXL on the biomechanical properties of human and porcine cornea. Riboflavin (vitamin B2) is a photosensitizer with an absorption peak for ultraviolet (UV) A at a wavelength of $370 \mathrm{~nm}$. The molecule fluoresces and excites to a triplet state when exposed to UV radiation of this wavelength, with subsequent release of singlet oxygen and superoxide radicals. In a cornea saturated with riboflavin, there will be a formation of new covalent bonds between collagen molecules by oxidative deamination. It has proved its efficacy in arresting progression of keratoconus. ${ }^{35-37}$

A limited number of studies and case reports have been published describing the effect of CXL in PMD. All showed improvement and/or stabilization of visual acuity and keratometric parameters. ${ }^{38-41}$ The CXL was also combined with topography-guided transepithelial surface ablation and showed improvement of visual outcome. However, the follow-up period was 12 months. $^{42}$

Koller et $\mathrm{al}^{43}$ examined the peripheral effect of CXL by evaluation of the stromal demarcation line by OCT, and they concluded that the targeted depth of CXL using current light sources is achieved within the central area 
only. In addition, they recommended that in order to provide CXL to the peripheral cornea, we need to decenter or change the intensity of the UV beam. Moreover, one of the main limiting factors for CXL with PMD is perilimbal location of ectatic thinning, and precautions should be undertaken to ensure the limbal stem cell protection from UVA exposure. All these factors make the efficacy and safety of CXL in PMD questionable, considering that most of the reported studies had limited number of patients and had short-term follow-up.

\section{TORIC IOL}

Several case reports ${ }^{44-46}$ and case series ${ }^{47}$ have been published regarding the use of toric IOL as phakic IOL or after phacoemulsification. Analysis of these case reports suggests that a careful case selection can yield good results from the use of toric IOL in PMD. A case of PMD with poor spectacle-corrected visual acuity is not a good candidate for toric IOL implantation, due to high concurrently existing corneal aberrations. Another major concern about toric IOL is the progression of ectasia and astigmatism after the procedure.

Those who had good spectacle-corrected visual acuity prior to the onset of cataracts, those who had never needed to use contact lenses, and those who have well-centered corneal astigmatism and symmetric axes are ideal candidates for possible toric IOLs.

\section{CORNEA REPLACEMENT SURGERY}

The different corneal surgical procedures described in literature are full thickness or PKP: Oversized central PKP/inferiorly decentered PKP, central/crescentic LK, simultaneous central PKP and inferior peripheral LK, intrastromal LK, crescentic wedge resection, epikeratophakia, and thermokeratoplasty.

Varley et $\mathrm{al}^{48}$ and Speaker et $\mathrm{al}^{49}$ published a series of cases of PMD treated with large diameter/inferiorly decentered PKP. The long-term results show good outcomes in term of visual acuity and graft survival, but had high incidence of endothelial rejection (7 out of 11 eyes ${ }^{48}$ and 4 out of 10 eyes $^{49}$ ). This high rejection rate is due to proximity to limbal blood vessels. Proximity to limbus can also result in increased risks of corneal neovascularization and suture-induced complications. ${ }^{50}$

"Tuck In" LK, which includes a central LK with intrastromal tucking of the peripheral flange was reported by Vajpayee et $\mathrm{al}^{51}$ as an effective surgical modality for the management of ectatic corneal disorders with peripheral corneal thinning. Moreover, this technique can avoid the damage to inferior limbal stem cells as compared with large diameter/inferiorly decentered PKP/deep anterior lamellar keratoplasty in patients with PMD.
Crescentic LK was also reported as a treatment option for PMD. But one of the major drawbacks is high postoperative astigmatism, which may necessitate central corneal grafting. If the PKP follows as a second procedure, then the risk of rejection is very high due to two different donor corneas. ${ }^{52,53}$

Rasheed and Rabinowitz ${ }^{54}$ described the efficacy of simultaneous peripheral crescentic LK and central PKP for advanced PMD. The short-term results of this case series are encouraging in terms of visual rehabilitation and postoperative astigmatic drift, but the procedure is technically complex.

Jabbarvand et $\mathrm{al}^{55}$ published a case series of 10 patients for whom intrastromal LK was performed for PMD. In this procedure, donor corneal stroma is cut into a crescent shape and inserted to crescent-shaped stromal pocket created at the area of thinning in host cornea. Even though the technique appears promising, there are many potential risks including the risk for perforation during lamellar dissection through the thinnest portion of the cornea, epithelial ingrowth, irregular astigmatism related to asymmetrical thickening, wrinkles in the lamellar graft, infection, stromal rejection, and extrusion of the graft.

MacLean et $\mathrm{al}^{56}$ reported the results of corneal wedge resection in 10 eyes. Corneal astigmatism was remarkably reduced (range 0.5-4.0 D), but the stability was short-lived. There was a progressive increase in the against-the-rule astigmatism, as much as $2.1 \mathrm{D}$ per year, in all the treated eyes. This is attributed to the instability of the corneal wound and acceleration of underlying disease process following wedge resection. Javadi et al ${ }^{57}$ described the results of lamellar crescentic resection in the surgical management of PMD in 15 eyes of 9 patients with a follow-up of 13 to 57 months (mean 35 months). Postoperatively, all the eyes had with-the-rule astigmatism with a long-term astigmatic drift: Mean 16.00 D at 6 weeks and $10.50 \mathrm{D}$ at 6 months, and in the second postoperative year, it was $4.30 \mathrm{D}$.

Even though lamellar or full-thickness crescentic wedge resection is an effective surgical method to manage PMD, visual recovery is relatively prolonged and the effect is short term.

The other rarely performed corneal surgery described for management of PMD is epikeratoplasty, a form of on-lay LK. ${ }^{50,58}$ In this surgery, a lenticule made of human corneal tissue is sutured onto the anterior corneal surface to change its anterior curvature and refractive properties.

\section{SUMMARY}

Early cases of PMD can be visually rehabilitated using spectacles or contact lenses. Scleral contact lens is a viable option for moderate-to-advanced PMD by which surgical intervention can be avoided. A wide range of surgical 
procedures have been reported until date, but all have their own limitations and questionable technical feasibilities. The ICRS and toric IOL are found to be useful only in a specific subset of patients. In short, careful clinical evaluation and tailoring of treatment to individual patients are the key to successful management of PMD.

\section{REFERENCES}

1. Krachmer JH, Feder RS, Belin MW. Keratoconus and related non inflammatory corneal thinning disorders. Surv Ophthalmol 1984 Jan-Feb;28(4):293-322.

2. Krachmer JH. Pellucid marginal corneal degeneration. Arch Ophthalmol 1978 Jul;96(7):1217-1221.

3. Sridhar M, Mahesh S, Bansal AK, Nutheti R, Rao G. Pellucid marginal corneal degeneration. Ophthalmology 2004 Jun;111(6):1102-1107.

4. Schlaeppi V. La dystrophie marginale inferierure pellucide de la cornee. Probl Actuels Ophtalmol 1957;12(47):672-677.

5. Basak SK, Hazra TK, Bhattacharya D, Sinha TK. Unilateral pellucid marginal degeneration. Indian J Ophthalmol 2000 Sep;48(3):233-234.

6. Kaushik S, Jain AK, Saini JS. Unilateral pellucid marginal degeneration. Eye (Lond) 2003 Mar;17(2): 246-248.

7. Sridhar MS, Mahesh S, Bansal AK, Rao GN. Superior pellucid marginal corneal degeneration. Eye (Lond) 2008 Apr;18(4):393-399.

8. Tzelikis PF, Cohen EJ, Rapuano CJ, Hammersmith KM, Laibson PR. Management of pellucid marginal corneal degeneration. Cornea 2005 Jul;24(5):555-560.

9. Robin JB, Schanzlin DJ, Verity SM, Barron BA, Arffa RC, Suarez E, Kaufman HE. Peripheral corneal disorders. Surv Ophthalmol 1986 Jul-Aug;31(1):1-36.

10. Rodrigues MM, Newsome DA, Krachmer JH, Eiferman RA. Pellucid marginal corneal degeneration: a clinicopathologic study of two cases. Exp Eye Res 1981 Sep;33(3):277-288.

11. Parker DL, McDonnell PJ, Barraquer J, Green WR. Pellucid marginal corneal degeneration. Cornea 1986;5(2):115-123.

12. Belin MW, Asota IM, Ambrosio R Jr, Khachikian SS. What's in a name: keratoconus, pellucid marginal degeneration, and related thinning disorders. Am J Ophthalmol 2011 Aug;152(2):157-162.

13. Mahadevan R, Amudhaoli A, Valarmathi A. Retrospective study of contact lens fitting in pellucid marginal degeneration. Eye Contact Lens 2008 Jul;34(4):207-210.

14. Dominguez CE, Shah A, Weissman BA. Bitoric gas-permeable contact lens application in pellucid marginal corneal degeneration. Eye Contact Lens 2005 Sep;31(5):241-243.

15. Gruenauer-Kloevekorn C, Fischer U, Kloevekorn-Norgall K, Duncker GI. Pellucid marginal corneal degeneration: evaluation of the corneal surface and contact lens fitting. Br J Ophthalmol 2006 Mar;90(3):318-323.

16. Visser ES, Visser R, van Lier HJ, Otten HM. Modern scleral lenses: part I: clinical features. Eye Contact Lens 2007 Jan;33(1):13-20.

17. Tan DT, Pullum KW, Buckley RJ. Medical applications of scleral contact lenses: a retrospective analysis of 343 cases. Cornea 1995 Mar;14(2):121-129.

18. Pullum KW, Buckley RJ. A study of 530 patients referred for rigid gas permeable scleral contact lens assessment. Cornea 1997 Nov;16(6):612-622.
19. Rathi VM, DumpatiS, Mandathara PS, Taneja MM, Sangwan VS. Scleral contact lenses in the management of pellucid marginal degeneration. Cont Lens Anterior Eye 2016 Jun;39(3):217-220.

20. Asena L, Altınörs DD. Clinical outcomes of scleral Misa lenses for visual rehabilitation in patients with pellucid marginal degeneration. Cont Lens Anterior Eye 2016 Dec;39(6):420-424.

21. Burris TE. Intrastromal corneal ring technology: results and indications. Curr Opin Ophthalmol 1998 Aug;9(4):9-14.

22. Fleming JF, Reynolds AE, Kilmer L, Burris TE, Abbott RL, Schanzlin DJ. The intra-stromal corneal ring: two cases in rabbits. J Refract Sug 1987 Nov;3(6):227-232.

23. Fleming JF, Lee Wan W, Schanzlin DJ. The theory of corneal curvature change with the intra-stromal corneal ring. CLAO J 1989 Apr-Jun;15(2):146-150.

24. Patel S, Marshall J, Fitzke FW 3rd. Model for deriving the optical performance of the myopic eye corrected with an intracorneal ring. J Refract Surg 1995 Jul-Aug;11(4):248-252.

25. Rodriguez-Prats J,Galal A, Garcia-Lledo M, Dela HozF, AlióJL. Intracorneal rings for the correction of pellucid marginal degeneration. J Cataract Refract Surg 2003 Jul;29(7):1421-1424.

26. Kymionis GD, Aslanides IM, Siganos CS, Pallikaris IG. Intacs for early pellucid marginal degeneration. J Cataract Refract Surg 2004 Jan;30(1):230-233.

27. Akaishi L, Tzelikis PF, Raber IM. Ferrara intracorneal ring implantation and cataract surgery for the correction of pellucid marginal corneal degeneration. J Cataract Refract Surg 2004 Nov;30(11):2427-2430.

28. Barbara A, Shehadeh-Masha'our R, Zvi F, Garzozi HJ. Management of pellucid marginal degeneration with intracorneal ring segments. J Refract Surg 2005 May-Jun;21(3):296-298.

29. Mularoni A, Torreggiani A, di Biase A, Laffi GL, Tassinari G. Conservative treatment of early and moderate pellucid marginal degeneration: a new refractive approach with intracorneal rings. Ophthalmology 2005 Apr;112(4):660-666.

30. Kubaloglu A, Sari ES, Cinar Y, Koytak A, Kurnaz E, Piñero DP, Ozerturk Y. A single 210-degree arc length intrastromal corneal ring implantation for the management of pellucid marginal corneal degeneration. Am J Ophthalmol 2010 Aug;150(2):185.e1-192.e1.

31. Ertan A, Bahadir M. Intrastromal ring segment insertion using a femtosecond laser to correct pellucid marginal corneal degeneration. J Cataract Refract Surg 2006 Oct;32(10): 1710-1716.

32. Ertan A, Bahadir M. Management of superior pellucid marginal degeneration with a single intracorneal ring segment using femtosecond laser. J Refract Surg 2007 Feb;23(2): 205-208.

33. Piñero DP, Alio JL. Intracorneal ring segments in ectatic corneal disease - a review. Clin Exp Ophthalmol 2010 Mar; 38(2):154-167.

34. Wollensak G, Spoerl E, Seiler T. Riboflavin/ultraviolet-a induced collagen crosslinking for the treatment of keratoconus. Am J Ophthalmol 2003 May;135(5):620-627.

35. Snibson GR. Collagen cross-linking: a new treatment paradigm in corneal disease - a review. Clin Exp Ophthalmol 2010 Mar;38(2):141-153.

36. McCall AS, KraftS, Edelhauser HF, Kidder GW, Lundquist RR, Bradshaw HE, Dedeic Z, Dionne MJ, Clement EM, Conrad GW. Mechanisms of corneal tissue cross-linking in response to treatment with topical riboflavin and long-wavelength ultraviolet radiation (UVA). Invest Ophthalmol Vis Sci 2010 Jan;51(1):129-138. 
37. Sorkina N, Varssano D. Corneal collagen, crosslinking: a systematic review. Ophthalmologica 2014 Apr;232(1):10-27.

38. Steppat,MH.;Raiskup-Wolf, F.;Sporl, E.;Hoyer, A.;Pillunat,LE. Collagen cross linking in patients with pellucid marginal degeneration. Proceedings of the ARVO Meeting, April-May 2008, Florida, USA. 2008.

39. Kymionis GD,Karavitaki AE, KounisGA, PortaliouDM, YooSH, Pallikaris IG. Management of pellucid marginal corneal degeneration with simultaneous customized photorefractive keratectomy and collagen crosslinking. J Cataract Refract Surg 2009 Jul;35(7):1298-1301.

40. Spadea L. Corneal collagen cross-linking with riboflavin and UVA irradiation in pellucid marginal degeneration. J Refract Surg 2010 May;26(5):375-377.

41. Hassan Z, Nemeth G, Modis L, Szalai E, Berta A. Collagen cross-linking in the treatment of pellucid marginal degeneration. Indian J Ophthalmol 2014 Mar;62(3):367-370.

42. Stojanovic A, Zhang J, Chen X, Nitter TA, Chen S, Wang Q. Topography-guided transepithelial surface ablation followed by corneal collagen cross-linking performed in a single combined procedure for the treatment of keratoconus and pellucid marginal degeneration. J Refract Surg 2010 Feb;26(2):145-152.

43. Koller T, Schumacher S, Fankhauser F 2nd, Seiler T. Riboflavin/ultraviolet a crosslinking of the paracentral cornea. Cornea 2013 Feb;32(2):165-168.

44. Han DCY, Lim L. Implantation of toric intraocular lens in pellucid marginal degeneration: a case report on ocular aberrometry outcome. J Clin Exp Ophthalmol 2012 Jan;3:204.

45. Bahar I, Bialer O. Cataract extraction and Toric intraocular lens implantation for the management of Pellucid marginal degeneration and cataract. Int J Keratoco Ectatic Corneal Dis 2012 Jan-Apr;1(1):66-67.

46. de Vries NE, Tahzib NG, Webers CA, Hendrikse F, Nuijts RM. Use of verisyse/artisan phakic intraocular lens for the reduction of myopia in a patient with pellucid marginal degeneration. Cornea 2008 Feb;27(2):241-245.

47. Camoriano GD, Aman-Ullah M, Purba MK, Sun J, Gimbel HV. Toric collagen copolymer phakic intraocular lens to correct myopic astigmatism in eyes with pellucid marginal degeneration. J Cataract Refract Surg 2012 Feb;38(2):256-261.

48. Varley GA, Macsai MS, Krachmer JH. The results of penetrating keratoplasty for pellucid marginal corneal degeneration. Am J Ophthalmol 1990 Aug;110(2):149-152.

49. Speaker MG, Arentsen JJ, Laibson PR. Long-term survival of large diameter penetrating keratoplasties for keratoconus and pellucid marginal degeneration. Acta Ophthalmol Suppl 1989;192:17-19.

50. Jinabhai A, Radhakrishnan H, O'Donnell C. Pellucid corneal marginal degeneration: a review. Contact Lens Anterior Eye 2011 Apr;34(2):56-63.

51. Kaushal S, Jhanji V, Sharma N, Tandon R, Titiyal JS, Vajpayee RB. "Tuck In" lamellar keratoplasty (TILK) for corneal ectasias involving corneal periphery. Br JOphthalmol 2008 Feb;92(2):286-290.

52. Schanzlin DJ, Sarno EM, Robin JB. Crescentic lamellar keratoplasty for pellucid marginal degeneration. Am J Ophthalmol 1983 Aug;96(2):253-254.

53. Kremer I, Sperber LT, Laibson PR. Pellucid marginal degeneration treated by lamellar and penetrating keratoplasty. Arch Ophthalmol 1993 Feb;111(2):169-170.

54. Rasheed K, Rabinowitz YS. Surgical treatment of advanced pellucid marginal degeneration. Ophthalmology 2000 Oct;107(10):1836-1840.

55. Jabbarvand M, Hashemian H, Khodaparast M, Hassanpour N, Mohebbi M. Intrastromal lamellar keratoplasty in patients with pellucid marginal degeneration. J Cataract Refract Surg 2015 Jan;41(1):2-8.

56. MacLean H, Robinson LP, Wechsler AW. Long-term results of corneal wedge excision for pellucid marginal degeneration. Eye (Lond) 1997;11(Pt 5):613-617.

57. Javadi MA, Karimian F, Hosseinzadeh A, Noroozizadeh HM, Sa'eedifar MR, Rabie HM. Lamellar crescentic resection for pellucid marginal corneal degeneration. J Refract Surg 2004 Mar-Apr;20(2):162-165.

58. Fronterre A, Portesani GP. Epikeratoplasty for pellucid marginal corneal degeneration. Cornea 1991 Sep;10(5):450-453. 